\title{
A New High-Voltage Electric Field Instrument for Studying Sprites
}

\author{
Jeremy N. Thomas, Robert H. Holzworth, and John Chin
}

\begin{abstract}
The high-voltage (HV) electric field detector is a new high-voltage, high-impedance, double Langmuir probe instrument designed for stratospheric electric field measurements. In the Sprite Balloon Campaign 2002-2003, this HV instrument was used to measure electric fields between 100 and $200 \mathrm{~V} / \mathrm{m}$ associated with lightning discharges, which is nearly an order of magnitude higher than previously reported above $30 \mathrm{~km}$ in altitude. This increased range is made possible by the availability of new low-leakage HV operational amplifiers. This is a critical instrument, since a large quasi-dc electric field associated with positive cloud-to-ground lightning is a primary component of most sprite generation mechanisms. The difficulty that exists when making electric field measurements in the high-resistance environment of the stratosphere is presented, and how this difficulty is remedied is described. The HV detector is compared to another electric field instrument, the low-voltage detector, used simultaneously on the Sprite Balloon Campaign to verify the accuracy of the $\mathrm{HV}$ probes. Finally, a large field perturbation $\left(E_{z} \approx-101 \mathrm{~V} / \mathrm{m}\right.$ and $\left.E_{x} \approx 79 \mathrm{~V} / \mathrm{m}\right)$ measured by the $\mathrm{HV}$ detector during Flight 1 , correlated with nearby $+15-\mathrm{kA}$ and $+53-\mathrm{kA}$ cloud-to-ground strokes, is presented.
\end{abstract}

Index Terms-Atmospheric electricity, double Langmuir probe, electric field detector, lightning, sprites.

\section{INTRODUCTION}

\section{A. Historical Background}

$\mathbf{T}$ HE HIGH-VOLTAGE (HV) electric field detector uses the double Langmuir probe technique, first used (at much lower voltages) for atmospheric studies by Kellogg and Weed [2] and Mozer and Serlin [3], to measure electric fields in the stratosphere. This technique has been used by various researchers to study electric fields associated with auroral activity, thunderstorms, and fair weather (e.g., [4]-[10]). Although, all of these double Langmuir probes, limited by the operational voltage of the preamplifiers used, measured electric fields less than about $\pm 10 \mathrm{~V} / \mathrm{m}$.

Field mill technology, rather than the double Langmuir probe technique, has been used to measure atmospheric electric fields below about $20 \mathrm{~km}$ in altitude. Field mill measurements of up to $5 \mathrm{kV} / \mathrm{m}$ have been made over thunderstorms from U-2 airplanes at 15-20-km altitude [11]. Balloon-borne field mills have also been flown through thunderclouds measuring fields up to $200 \mathrm{kV} / \mathrm{m}$ below $10 \mathrm{~km}$ in altitude [12]. However, since the local relaxation time is only a few seconds at altitudes above

Manuscript received August 27, 2003; revised February 19, 2004. This research was supported by the National Science Foundation under Grants ATM0091825 and ATM-9987684.

The authors are with the Department of Earth and Space Sciences, University of Washington, Seattle, WA 98195-1310 USA (e-mail: jnt@u.washington.edu).

Digital Object Identifier 10.1109/TGRS.2004.826806
$25-30 \mathrm{~km}$, the field mill method cannot be used to measure electric fields in this region of the stratosphere. This is because the field mill can only measure fields accurately if it has a rotation (or shutter speed, etc.) that is very fast with respect to the local relaxation time; otherwise the field mill will short out the field. This new HV detector, utilizing new high-voltage, high input impedance operational (op) amplifiers, is capable of measuring potential differences up to $240 \mathrm{~V}$, at altitudes above the field mill regime, to study lightning discharges and/or sprites. Note that Bering et al. [13] did report using a balloon-borne detector above $30 \mathrm{~km}$ in altitude with a dynamic range of $\pm 100 \mathrm{~V} / \mathrm{m}$, but the only events requiring use of this instrument were triboelectric episodes involving ballast drops coming close to the payload.

\section{B. Why Is the HV Detector Needed to Study Sprites?}

The HV detector was developed specifically to study electric fields in the stratosphere related to high-altitude discharges known as sprites. Sprites are transient luminous events (TLEs) that occur between $40-90 \mathrm{~km}$ in altitude above thunderstorms [14]-[16]. Most sprite generation models involve a large quasi-static electric field that forms between the top of large thunderclouds and the ionosphere as a result of large positive cloud-to-ground lightning strokes (peak current approximately $>30-50 \mathrm{kA}$ ) (cf. [17] and references therein). However, the strength of this field near a sprite $(<100 \mathrm{~km})$ has never been measured. Some models rely only on the quasi-static electric field to cause the dielectric breakdown that produces the sprites [18]. Other models incorporate runaway electrons, possibly initiated by cosmic rays, and accelerated by the quasi-static electric field to create breakdown [19]. The models that include these runaway electrons require a weaker field than models that rely only on the quasi-static electric field. Hence, the magnitude of this quasi-static field that is measured will support either of these models or suggest a new model.

A previous balloon-borne experiment conducted by Bering et al. [13] measured a vertical field perturbation of $E_{z} \approx 0.275 \mathrm{~V} / \mathrm{m}$ at a distance of about $379 \mathrm{~km}$ from a sprite. Assuming a $r^{-n}(n=1,2$, or 3$)$ electric field dependence, this suggests that a near field measurement $(<50 \mathrm{~km})$ will have a magnitude of up to $10-100 \mathrm{~V} / \mathrm{m}$. The $\mathrm{HV}$ detector measured electric field changes in this range correlated with positive cloud-to-ground lightning but without the confirmation of sprites.

During Sprite Flight 1 on December 6 and 7, 2002, the $\mathrm{HV}$ instrument measured a vertical field perturbation of $E_{z} \approx-101 \mathrm{~V} / \mathrm{m}$ and a horizontal field perturbation of $E_{x} \approx 79 \mathrm{~V} / \mathrm{m}$ correlated with nearby $+15-\mathrm{kA}$ and +53 -kA 
ground strokes (as is discussed in more detail in Section III-C). Thus, the HV electric field detector, with a range of up to about $195 \mathrm{~V} / \mathrm{m}$, has proved to be an important component of balloon-borne thunderstorm research.

\section{High-Voltage Electric Field Instrument}

\section{A. Basics of the Double Langmuir Probe Technique}

The double Langmuir probe technique allows for the measurement of large-scale electric fields in the atmosphere with field frequencies limited by the slew rate of the op amplifiers used. This technique consists of two conductors (spheres, plates, or cylinders) each with a sufficiently large surface area to collect enough charge to drive the electronics. These conductors are separated by a distance $d$, which enables the probes to be adequately far from the central payload $(>1 \mathrm{~m})$ to reduce field anomalies caused by the payload structure. By measuring the potential difference between the two conductors $\left(V_{21} \equiv V_{2}-V_{1}\right)$ and dividing by the distance between the probes $d$, the electric field component $\left(E_{21}=V_{21} / d\right)$ in the direction from probe 2 to probe 1 is determined. By orienting pairs of probes in three orthogonal directions, the vector electric field $\vec{E}$ is found.

\section{B. Hardware for the HV Detector}

The HV probes, or charge collectors, developed for the Sprite Campaign 2002-2003 are $20 \mathrm{~cm}$ long $\times 4 \mathrm{~cm}$ diameter cylindrical conductors placed on four booms to give voltage difference measurements of up to $\pm 240 \mathrm{~V}$ along two independent directions, one vertical and one horizontal. Cylindrical conductors are used, since they are cheaper and easier to fabricate than spheres. However, this shape does result in a different antenna factor for the HV cylindrical probes relative to the low-voltage (LV) spherical probes as discussed in Section III-B. The cylinders are placed on fiberglass booms extending vertically and horizontally from the balloon gondola, and they are connected to high-voltage, high input impedance preamplifiers (see Section II-C) housed inside the gondola by Teflon coaxial cable (RG-188). The coaxial shield is driven by the unity gain op amplifier output to eliminate a voltage drop between the inner and outer conductors of the cable, thus preventing a large load capacitance from forming and at the same time reducing leakage current. The total voltage difference between probes, divided by the separation distance between the probes $(1.56 \mathrm{~m}$ on the vertical axis and $2.0 \mathrm{~m}$ on the horizontal axis) is the vector electric field component, $E_{z}$ or $E_{x}$. Four vertical metal plates are placed around the gondola to form a symmetric ground configuration for the probes (see Fig. 1 for a sketch of the sprite payload configuration). The vertical probes can measure fields up to about $154 \mathrm{~V} / \mathrm{m}$ with a resolution of about $0.08 \mathrm{~V} / \mathrm{m}$, and the horizontal probes can measure fields up to about $120 \mathrm{~V} / \mathrm{m}$ with a resolution of about $0.06 \mathrm{~V} / \mathrm{m}$. This gives a maximum two-component field magnitude of about $195 \mathrm{~V} / \mathrm{m}$. Note that the instrument could measure higher electric fields by reducing the probe separation. However, this is limited by the requirement that the probes must be far enough from the central payload to prevent field distortions caused by the gondola structure.

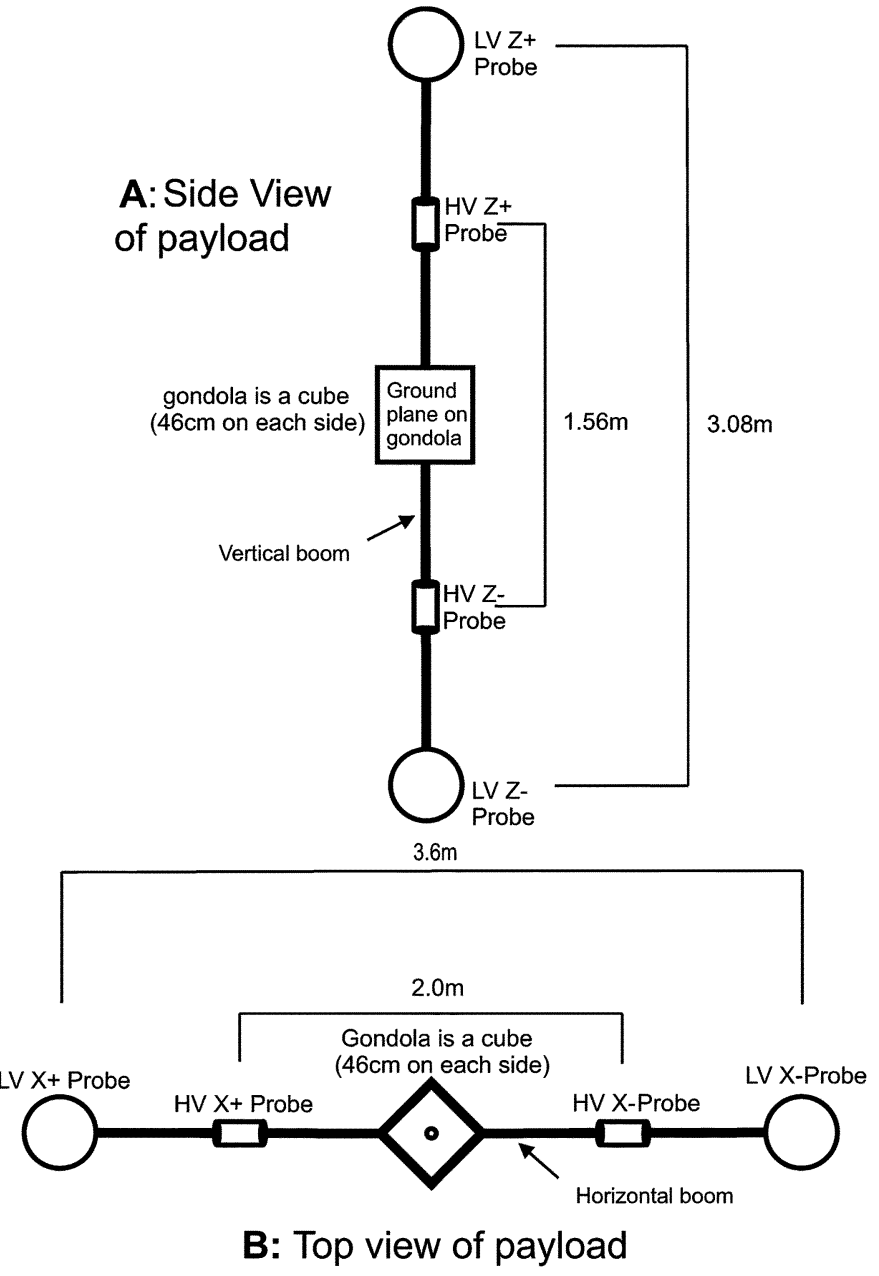

Fig. 1. Sketch of the sprite payload configuration (not to scale). (A) Side view of the payload without the horizontal booms. The HV and LV vertical electric field probes are indicated. (B) Top view of the payload with only the one horizontal boom (the other horizontal boom is identical except that it has only LV probes). The HV and LV horizontal electric field probes are indicated.

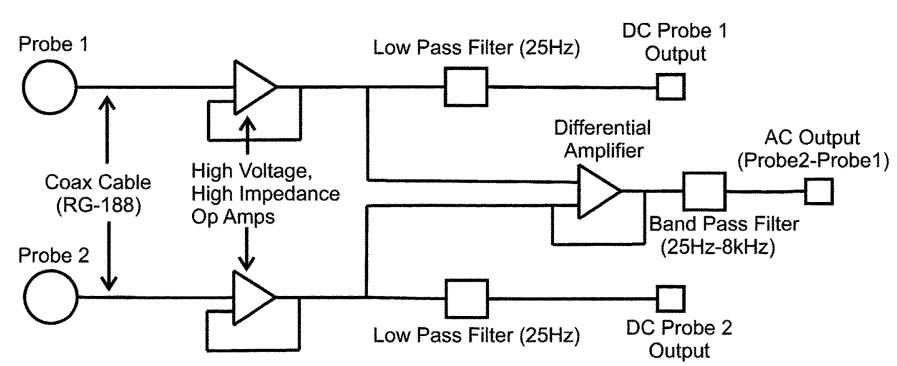

Fig. 2. Block diagram of the key components of the HV detector layout.

The HV instrument measures quasi-dc and VLF ac electric fields. This is just one measurement with different sampling rates for the quasi-dc ( $\sim 300$ samples/s) and the VLF ac $(20 \mathrm{k}$ samples/s) fields. The quasi-dc channels utilize a lowpass filter for a 3-dB attenuation at about $25 \mathrm{~Hz}$, and the VLF ac channels use a bandpass filter with 3-dB attenuation at about $25 \mathrm{~Hz}$ and $8 \mathrm{kHz}$ (see Fig. 2 for a block diagram of key components of the HV detector layout). Hence, the HV detector provides both a quasi-dc and a VLF ac waveform for lightning and sprite events. 


\section{Difficulty of Stratospheric Electric Field Measurements}

1) High Resistance of the Atmosphere: Measuring electric fields in the atmosphere is difficult, since the atmospheric resistance is so large. Mozer and Serlin [3] compute this resistance between the atmosphere and a charge collecting probe to be

$$
R_{\mathrm{atm}}=\frac{m_{i} \nu_{i}}{4 \pi n_{i} e^{2} r_{0}}
$$

where $m_{i}$ is the ion mass, $\nu_{i}$ is the ion-neutral collision frequency, $n_{i}$ is the ion density, $e$ is the charge of the electron, and $r_{0}$ is the radius of a spherical probe (note that the equation for the atmospheric resistance in Mozer and Serlin [3] erroneously includes the neutral mass $m_{n}$ rather than the ion mass $m_{i}$ ). Hence, for a 30 -cm diameter sphere $\left(r_{0}=15 \mathrm{~cm}\right)$ at the surface of the earth $R_{\text {atm }} \approx 10^{13} \cdot \Omega$, and at a 32-km altitude $R_{\text {atm }} \approx 10^{11} \cdot \Omega$ [3].

2) Remedy: High-Voltage, High Input Impedance, Operational Amplifiers: So what does this high atmospheric resistance mean for the HV electronics? In order to measure the potential difference between two points in the stratosphere accurately (better than 10\%), there must be sufficiently high input impedance $R_{\text {in }}$ for the electronics. If this input impedance is low compared to the atmospheric resistance $R_{\text {atm }}$, then the $\mathrm{HV}$ detector will effectively short out the field that it is trying to measure. Thus, an accurate stratospheric electric field measurement requires that $R_{\text {in }} \gg R_{\text {atm }}$ [3].

Hence, the key to making voltage measurements (or electric field measurements) in the atmosphere is to have a high input impedance yet still draw enough current to drive the electronics. To accomplish this impedance transform, a high-voltage, high input impedance, low output impedance op amplifier (Apex Corporation, PA141) is connected to the probe in a unity gain voltage follower circuit (see Fig. 2 for a block diagram of key components of the $\mathrm{HV}$ detector layout). By measuring the RC time constant of the op amp in series with a $10-\mathrm{pF}$ capacitor, the effective input impedance of this op amp is determined to be greater than $10^{14} \Omega$, and thus $R_{\text {in }}>10^{3} \times R_{\text {atm }}$, which is more than sufficient for field measurement accuracy of better than $10 \%$. The availability of these high-voltage, high input impedance op amplifiers allows for more than an order of magnitude increase in the dynamic range of the double Langmuir probe technique for measuring electric fields.

\section{Power Supply for the HV Detector}

Two voltage measurements of up to $\pm 120 \mathrm{~V}$, each using the op amplifier described in Section II-C, are made to calculate the potential difference up to $\pm 240 \mathrm{~V}$ between any pair of separated conductors. Instead of including costly \pm 120 - $\mathrm{V}$ batteries on the payload to power these op amplifiers, a new dual power supply was developed that converts $+15 \mathrm{~V}$ to $\pm 120 \mathrm{~V}$. This new power supply has an efficiency of about $80 \%$, and it varies by less than $1 \mathrm{~V}$ in supplying approximately $\pm 120 \mathrm{~V}$ for temperatures between $-70{ }^{\circ} \mathrm{C}$ and $50{ }^{\circ} \mathrm{C}$. This power supply can provide $6 \mathrm{~mA}$ at $120 \mathrm{~V}$ and $6 \mathrm{~mA}$ at $-120 \mathrm{~V}$, which is ample to follow rail-to-rail input voltages to the op amplifiers at $10 \mathrm{kHz}$. Designed for lightweight balloon payloads, this power supply uses only $43 \mathrm{~cm}^{2}$ of space on the HV detector printed circuit boards with a nominal mass of less than $10 \mathrm{~g}$ (see Table I for power supply specifications).
TABLE I

POWER SUPPLY SPECIFICATIONS

\begin{tabular}{l|r}
\hline Temperature Range Tested & $-70^{0}$ to $50^{0} \mathrm{C}$ \\
\hline Input Voltage & $15 \mathrm{~V}$ \\
\hline Quiescent Input Current at $25^{0} \mathrm{C}$ & $43 \mathrm{~mA}$ \\
\hline Input Current Temperature Coefficient & $<0.2 \mathrm{~mA} /{ }^{0} \mathrm{C}$ \\
\hline Output Voltage at $25^{0} \mathrm{C}$ & $\pm 119.4 \mathrm{~V}$ \\
\hline Output Voltage Stability at $25^{0} \mathrm{C}$ & $>99.9 \%$ \\
\hline Output Voltage Temperature Coefficient & $<0.01 \mathrm{~V} /{ }^{0} \mathrm{C}$ \\
\hline Output Voltage AC Noise & $<0.003 \mathrm{~V} \mathrm{RMS}$ \\
\hline Maximum Output Current (per side) & $6 \mathrm{~mA}$ \\
\hline Maximum Output Power (per side) & $0.72 \mathrm{~W}$ \\
\hline Efficiency & $\sim 80 \%$ \\
\hline Dimensions & $9.5 \mathrm{~cm} \times 4.5 \mathrm{~cm}$ \\
\hline Mass & $<10 \mathrm{~g}$ \\
\hline
\end{tabular}

III. High-Voltage Electric Field Measurements During THE SPRITE BALlOON CAMPAIGN 2002-2003

\section{A. Sprite Balloon Campaign 2002-2003}

The objective of the Sprite Balloon Campaign 2002-2003 [1] was to obtain in situ measurements, in the stratosphere, of the electromagnetic signature above sprite producing thunderstorms. The campaign included two balloon flights (December 6 and 7, 2002 and March 6 and 7, 2003) each launched from Cachoeira Paulista ( $\left.22^{\circ} 44^{\prime} \mathrm{S}, 44^{\circ} 56^{\prime} \mathrm{W}\right)$, Brazil. During the two flights, the electric and magnetic field signatures of hundreds of lightning events were measured by the payloads, including some of the largest vector electric fields ever measured over intense thunderstorms above $30 \mathrm{~km}$ in the stratosphere. Unfortunately, sprites have yet to be confirmed during these flights because the optical imager mounted on an airplane was hindered by heavy cloud coverage (Flight 1), or the observation airplane was unable to take off due to severe local weather (Flight 2). Although, during this campaign, sprites were imaged for the first time from Brazil but not simultaneous to the balloon flights (see [20]).

\section{B. Comparison Between $H V$ and $L V$ Detectors}

During Sprite Flight 1, hundreds of transient electric field perturbations were measured by the HV and LV instruments, with most of these events correlated with lightning events through the onboard flash detector and/or the Brazilian Integrated Network (BIN) [21], the integration of three groundbased regional lightning detection networks that covers the Southeast of Brazil. In this section, the HV and LV detectors are compared during two time intervals when no lightning-induced field perturbations occurred (since the LV detector usually saturates during periods of lightning, giving invalid readings) to insure that the HV instrument is accurately measuring these field perturbations. Since the HV and LV detectors have 

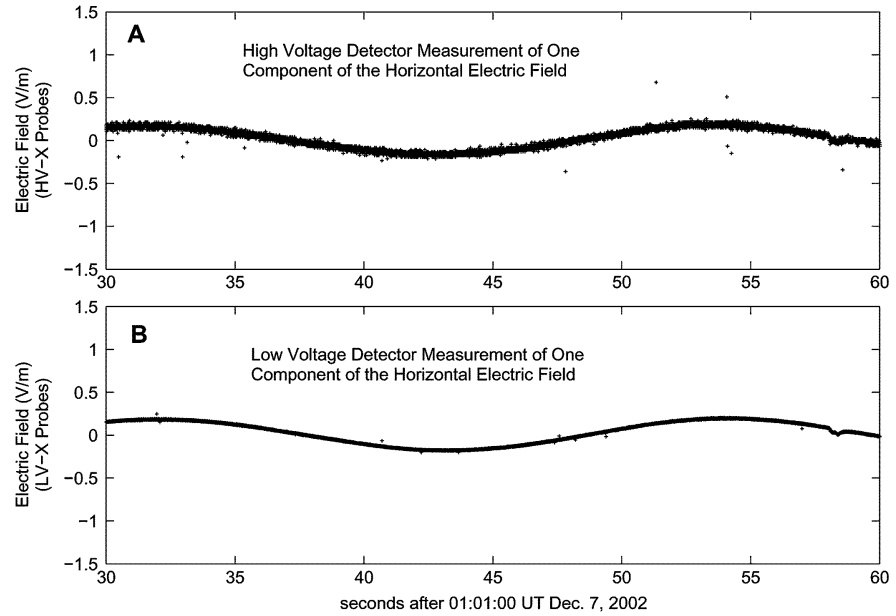

Fig. 3. Comparison of high-voltage and low-voltage horizontal electric field detectors during an inactive storm period. (A) High-voltage detector measurement of one component of the horizontal field. (B) Low-voltage detector measurement of one component of the horizontal field.

completely independent probes and electronics, this is a valid test of the new HV instrument.

Figs. 3 and 4 show examples of one component of the horizontal dc electric field measured by the HV detector [Figs. 3(A) 4(A)] and LV detector [Figs. 3(B) and 4(B)] for two different time intervals during Sprite Flight 1 on December 7, 2002. The HV horizontal field data have been multiplied by the effective antenna length factor of 0.70 to account for geometrical differences in the field caused by the different locations of the $\mathrm{HV}$ and $\mathrm{LV}$ probes relative to the ground planes on the gondola and the cylindrical shape of the HV probes. Since the LV technique has been shown to accurately measure electric fields in past experiments (as discussed in Section I-A), the HV detector was calibrated by matching its measurements to the $\mathrm{LV}$ detector.

Fig. 3 presents dc horizontal field data for a 30 -s interval beginning at 01:00:30 UT when there was no nearby $(<100 \mathrm{~km})$ lightning activity; thus, the one component of the background horizontal electric field was only about $0.175 \mathrm{~V} / \mathrm{m}$. Note that the balloon payload was rotated with a period of about $22 \mathrm{~s}$, which causes the constant single component of the horizontal field to appear sinusoidal. Since the LV detector was designed to measure smaller fields $(0.001-8 \mathrm{~V} / \mathrm{m})$ than the $\mathrm{HV}$ detector, variations of \pm 1 telemetry unit are much more evident in the $\mathrm{HV}$ field data [Fig. 3(A)] than the LV data [Fig. 3(B)]. But even for this small background field the HV instrument (which was not optimized to measure such small fields) and LV instrument were consistent, with the rotation of the balloon seen in the field data. Fig. 4 shows one component of the horizontal dc electric field data for a 30-s interval beginning at 02:09:00 UT when there was a strong thunderstorm nearby $(<100 \mathrm{~km})$; thus, the dc field was nearly $1 \mathrm{~V} / \mathrm{m}$, about six times larger than in Fig. 3. As in Fig. 3, the HV detector [Fig. 4(A)] and LV detector [Fig. 4(B)] were in good agreement, with the rotation of the payload evident. This consistency between the HV and LV detectors, which have completely separate probes and electronics, verifies that the $\mathrm{HV}$ instrument measurements of transient lightning electric field perturbations are reliable.
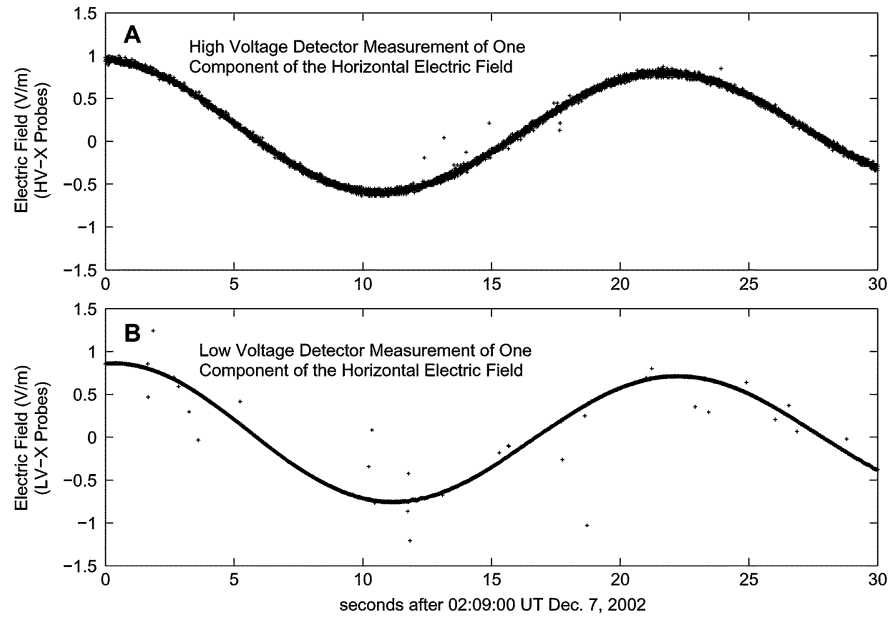

Fig. 4. Comparison of high-voltage and low-voltage horizontal electric field detectors during an active storm period. (A) High-voltage detector measurement of one component of the horizontal field. (B) Low-voltage detector measurement of one component of the horizontal field.

\section{A Large Electric Field Change During Sprite Flight 1 Correlated With Positive Lightning}

In this section, an example of the HV instrument measuring a large electric field change, correlated with positive lightning, is presented to show that the instrument can indeed measure such large field perturbations. This field change, the largest measured, occurred at an altitude of about $34 \mathrm{~km}$ at about 00:00:09 UT December 7, 2002 with a vertical dc field perturbation of $E_{z} \approx-101 \mathrm{~V} / \mathrm{m}$ (the negative vertical field value indicates a field directed downward, toward the earth) and a horizontal dc field perturbation of $E_{x} \approx 79 \mathrm{~V} / \mathrm{m}$. This field perturbation, the largest reported in the stratosphere above $30 \mathrm{~km}$, correlated with two cloud-to-ground lightning strokes, a +15-kA stroke (peak current) at 00:00:09.05 UT about $33.2 \mathrm{~km}$ from the payload (horizontal distance) and a +53 -kA stroke at 00:00:09.19 UT about $34.4 \mathrm{~km}$ from the payload, detected by BIN.

Fig. 5 shows the HV detector dc electric field data and the optical lightning data for these lightning events. The large vertical [Fig. 5(A)] and single component of the horizontal [Fig. 5(B)] dc electric field perturbations occurred simultaneously with the lightning strokes detected by BIN, indicated by dashed vertical lines on the figures, and the optical lightning data [Fig. 5(C)]. The $+15-\mathrm{kA}$ and $+53-\mathrm{kA}$ strokes perturbed the vertical dc field by $E_{z} \approx-32 \mathrm{~V} / \mathrm{m}$ and $E_{z} \approx-69 \mathrm{~V} / \mathrm{m}$, respectively, and these strokes perturbed the single component of the horizontal dc field by $E_{x} \approx 42 \mathrm{~V} / \mathrm{m}$ and $E_{x} \approx 37 \mathrm{~V} / \mathrm{m}$, respectively. Thus, the dc field perturbations add up to fields of $E_{z} \approx-101 \mathrm{~V} / \mathrm{m}$ and $E_{x} \approx 79 \mathrm{~V} / \mathrm{m}$. Note that these dc fields decayed slowly, taking more than $10 \mathrm{~s}$, or a few times the local relaxation time, to return to background values. Thus, nearby $(<50 \mathrm{~km})$ positive cloud-to-ground lightning strokes form large quasi-static electric fields in the stratosphere above $30 \mathrm{~km}$ that remain for long time periods $(\sim 10 \mathrm{~s})$.

Fig. 6 shows the ac electric field data from the HV detector along with the optical lightning data for these lightning events. The vertical and single-component horizontal ac electric 

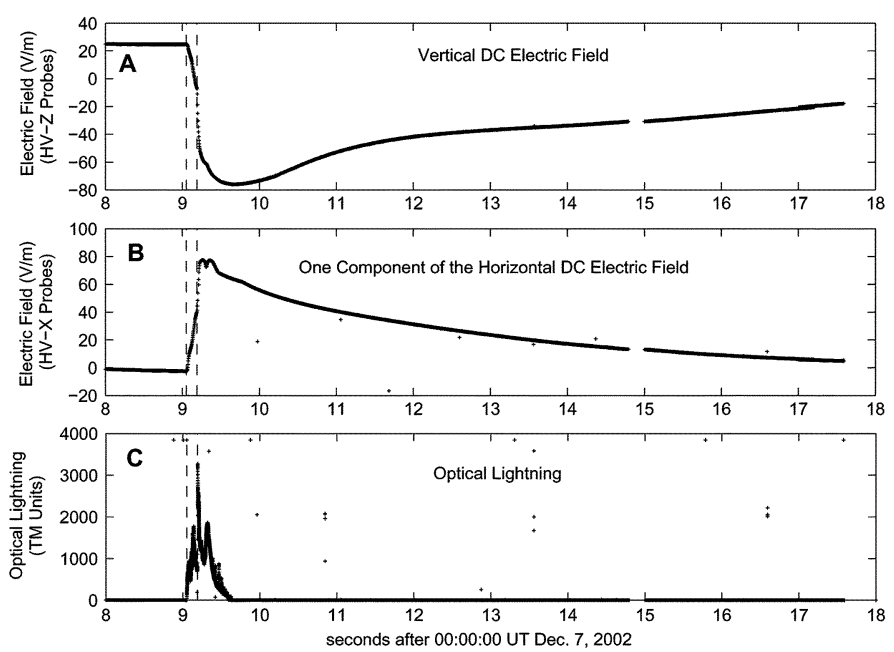

Fig. 5. Two lightning events, $+15 \mathrm{kA}$ and $+53 \mathrm{kA}$, at $\sim 00: 00: 09 \mathrm{UT}$ December 7, 2002, located $\sim 33.2 \mathrm{~km}$ and $\sim 34.4 \mathrm{~km}$ horizontal distance from the payload, respectively. (A) Vertical dc electric field. (B) One component of the horizontal dc electric field. (C) Optical lightning. The two lightning stroke times are indicated by the dashed vertical lines.
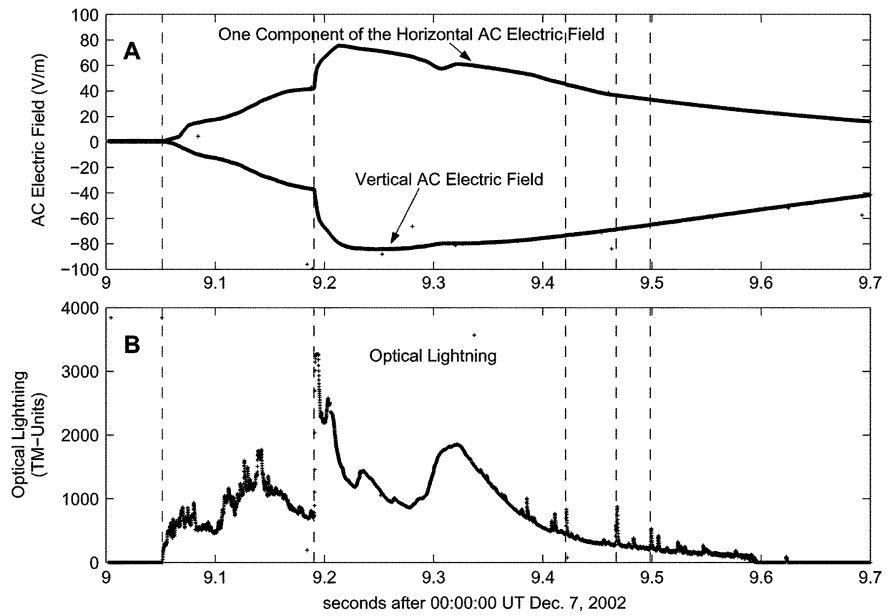

Fig. 6. Two lightning events, $+15 \mathrm{kA}$ and $+53 \mathrm{kA}$, at $\sim 00: 00: 09 \mathrm{UT}$ December 7, 2002 located $\sim 33.2 \mathrm{~km}$ and $\sim 34.4 \mathrm{~km}$ horizontal distance from the payload, respectively. (A) Vertical and horizontal (one component) ac electric field. (B) Optical lightning. Dashed vertical lines indicate lightning stroke times, note that three additional strokes are included here after the two strokes of interest.

field perturbations [Fig. 6(A)] occurred simultaneously to the lightning strokes, just as in Fig. 5. Note that the BIN lighting strokes are again shown as dashed vertical lines, and that an additional three strokes are included here that occurred after the two strokes of interest. These three strokes had little effect on the electric fields but can be seen in the optical lightning data [Fig. 6(B)]. The vertical and single-component horizontal ac field changes that correspond with the $+15-\mathrm{kA}$ and $+53-\mathrm{kA}$ strokes were similar in magnitude to the dc field changes shown in Fig. 5. Hence, low-frequency components dominated the electric field signature of these strokes. Further research into why positive strokes create such large, long lasting stratospheric electric fields could explain their correlation to sprite formation.

\section{CONCLUSION}

The HV detector is a double Langmuir probe instrument that utilizes an impedance transform, through the implementation of high-voltage, high input impedance op amplifiers, to enable electric field measurements up to about $195 \mathrm{~V} / \mathrm{m}$ in the stratosphere. During the Sprite Balloon Campaign 2002-2003, this HV instrument measured hundreds of transient field perturbations correlated with cloud-to-ground lightning, often when the the LV detector was saturated, unable to make field measurements. The accuracy of the HV detector is verified by comparison with the LV detector with excellent agreement at field values when they overlapped. Sprite Flight 1 measured one of the largest electric field perturbations ever reported in the stratosphere above $30 \mathrm{~km}\left(E_{z} \approx-101 \mathrm{~V} / \mathrm{m}\right.$ and $E_{x} \approx 79 \mathrm{~V} / \mathrm{m}$ ), which was correlated with two cloud-to-ground strokes with peak currents of $+15 \mathrm{kA}$ and $+53 \mathrm{kA}$ about $33.2 \mathrm{~km}$ and $34.4 \mathrm{~km}$ (horizontal distance), respectively, from the Sprite Flight 1 payload. Since sprite mechanisms rely on the formation of these large quasi-static electric fields in the atmosphere above thunderstorms, this HV detector is a vital instrument in future balloon-borne sprite research.

\section{ACKNOWLEDGMENT}

The authors thank O. Pinto, Jr. and the other members of the ELAT group at INPE (São Jose dos Campos, Brazil) for hosting them during the Sprite Balloon Campaign and supplying the BIN lightning data. They also thank M. McCarthy (University of Washington) for his valuable comments and suggestions, while preparing this paper.

\section{REFERENCES}

[1] R. H. Holzworth, M. P. McCarthy, J. N. Thomas, J. Chin, T. M. Chinowsky, M. J. Taylor, and O. Pinto, Jr., Strong electric fields from positive lightning strokes in the stratosphere, in Geophys. Res. Lett., submitted for publication.

[2] P. J. Kellogg and M. Weed, "Balloon measurements of ionospheric electric fields," in Proc. 4th Int. Conf. Universal Aspects of Atmospheric Electricity, Tokyo, Japan, 1968.

[3] F. S. Mozer and R. Serlin, "Magnetospheric electric field meaurements with balloons," J. Geophys. Res., vol. 74, pp. 4739-4754, Sept. 1969.

[4] E. A. Benbrook, J. W. Kern, and W. R. Sheldon, "Measured electric field in the vicinity of a thunderstorm at an altitude of $37 \mathrm{~km}$," J. Geophys. Res., vol. 79, pp. 5289-5294, Dec. 1974.

[5] R. H. Holzworth and F. S. Mozer, "Direct evidence of solar flare modification of stratospheric electric fields," J. Geophys. Res., vol. 84, pp. 363-367, Jan. 1979.

[6] E. A. Bering, T. J. Rosenberg, J. R. Benbrook, D. Detrick, D. L. Matthews, M. J. Rycroft, M. A. Saunders, and W. R. Sheldon, "Electric fields, electron precipitation, and VLF radiation during a simultanoeous magnetospheric substorm and atmospheric thunderstorm," J. Geophys. Res., vol. 85, pp. 55-72, Jan. 1980.

[7] I. R. C. A. Pinto, O. Pinto, Jr., W. D. Gonzalez, S. L. Dutra, J. Wygant, and F. S. Mozer, "Stratospheric electric field and conductivity measurements over electrified convective clouds in the South American region," J. Geophys. Res., vol. 93, pp. 709-715, Jan. 1988.

[8] $\mathrm{H} . \mathrm{Hu}$, "Global and local electrical phenomena in the stratopshere," Ph.D. Thesis, Geophys. Program, Univ. Washington, Seattle, WA, 1994.

[9] R. H. Holzworth and E. A. Bering, "Ionospheric electric fields from stratospheric balloon-borne probes," in Measurement Techniques in Space Plasmas: Fields, 1998, vol. 103, Geophysical Monographs, pp. 79-84. 
[10] M. M. F. Sabba, O. Pinto, Jr., I. R. C. A. Pinto, and O. Mendes, Jr., "Stratospheric balloon measurements of electric fields associated with thunderstorms and lightning in Brazil," J. Geophys. Res., vol. 105, pp. 18 091-18 097, July 2000.

[11] R. J. Blakeslee, H. J. Christian, and B. Vonnegut, "Electrical measurements over thunderstorms," J. Geophys. Res., vol. 94, pp. 13 135-13 140, Sept. 1989.

[12] T. C. Marshall, M. P. McCarthy, and W. D. Rust, "Electric field magnitudes and lightning initiation in thunderstorms," J. Geophys. Res., vol. 100, pp. 7097-7103, Apr. 1995.

[13] E. A. Bering, J. R. Benbrook, J. A. Garret, A. M. Paredes, E. M. Wescott, D. R. Moudry, D. D. Sentman, and H. C. Stenbaek-Nielsen, "The electrodynamics of sprites," Geophys. Res. Lett., vol. 29, pp. 8-1-8-4, 2002.

[14] D. D. Sentman, E. M. Wescott, D. L. Osborne, D. L. Hampton, and M. J. Heavner, "Preliminary results from the Sprites94 aircraft campaign, 1. Red sprites," Geophys. Res. Lett., vol. 22, pp. 1205-1208, May 1995.

[15] W. L. Boeck, O. H. Vaughan, and R. J. Blakeslee, "Low light level TV images of terrestrial lightning as viewed from space," Trans. Amer. Geophys. Union, vol. 72, p. 171, 1991.

[16] W. A. Lyons, "Characteristics of luminous structures in the stratosphere above thunderstorms as imaged by low-light video," Geophys. Res. Lett., vol. 21, pp. 875-878, May 1994.

[17] C. J. Rodger, "Red sprites, upward lightning, and VLF perturbations," Rev. Geophys., vol. 37, pp. 317-336, Aug. 1999.

[18] V. P. Pasko, U. S. Inan, T. F. Bell, and Y. N. Taranenko, "Sprites produced by quasi-electrostratic heating and ionization in the lower ionosphere," J. Geophys. Res., vol. 102, pp. 4529-4562, Mar. 1997.

[19] N. G. Lehtinen, T. F. Bell, V. P. Pasko, and U. S. Inan, "A two dimensional model of runaway electron beams driven by quasi-electrostatic thundercloud fields," Geophys. Res. Lett., vol. 24, pp. 2639-2642, Nov. 1997.

[20] M. J. Taylor, P. D. Pautet, M. Bailey, F. S. Sabbas, O. Pinto, R. H. Holzworth, and M. Sato, Investigating sprite energetics over Brazil in association with small/frontal storms, in Geophys. Res. Lett., submitted for publication.

[21] O. Pinto, Jr., I. R. C. A. Pinto, R. B. B. Gin, and O. Mendes, Jr., "Positive thunderstorms in Brazil," Ann. Geophys., vol. 16, pp. 353-355, Mar. 1998.

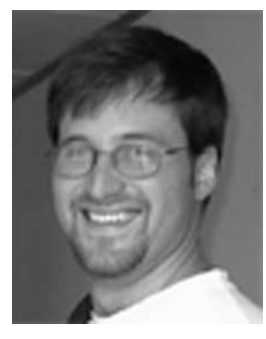

Jeremy N. Thomas received the B.A. degree from Bard College, Annandale-on-Hudson, NY, in 2000, and the M.S. degree from the University of Washington, Seattle, in 2002, both in physics. He is currently pursuing the Ph.D. degree at the University of Washington.

He was previously involved in neutrino physics research at the University of Oklahoma (1998), Los Alamos National Laboratory (1999), Bard College (1999-2000), and the University of the Witwatersrand, Johannesburg, South Africa (1999). Since 2001, he has been a member of the Space Physics Group, Department of Earth and Space Sciences, University of Washington, where has been involved in atmospheric electrodynamics research. His current interests include the electrodynamics of sprites and intense lightning, the time of group arrival (TOGA) lightning detection network, and X-ray measurements from triggered lightning. He hopes to return to Brazil to attempt another balloon-borne study of sprite electrodynamics in the near future.

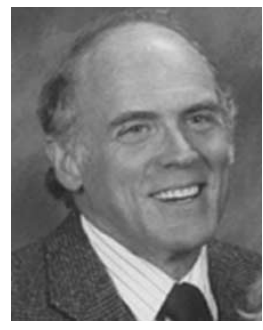

Robert H. Holzworth received the Ph.D. degree in physics from University of California, Berkeley, in 1977.

He was a Staff Scientist with Aerospace Corporation, Los Angeles, CA, until 1982, and has been on the faculty at the University of Washington, Seattle, since then. He holds appointments in both the Department of Earth and Space Sciences and the Department of Physics, where he conducts research in experimental space plasma physics and atmospheric electrodynamics.

John Chin is a retired Research Engineer who has been responsible for the primary payload instrument designs of over 50 stratospheric balloon payloads and several rocket and satellite instruments. He continues to work part time in the Space Physics Group, Department of Earth and Space Sciences, University of Washington, Seattle. 